\title{
Diálogos sobre a Educação de Jovens e Adultos: da exclusão à transformação social
}

\author{
Milena Moretto*
}

O presente ensaio tem como pretensão apresentar, a partir de uma investigação teórica, uma reflexão sobre as práticas escolares de exclusão social no que se refere à Educação de Jovens e Adultos (doravante EJA) e de como esse contexto pode e deve possibilitar uma transformação social daqueles que o frequentam. Consideremos, inicialmente, que, de acordo com a Lei de Diretrizes e Bases da Educação (1996), no artigo 4, inciso VII, é assegurada a

oferta de educação escolar regular para jovens e adultos, com características e modalidades adequadas às suas necessidades e disponibilidades, garantindo-se aos que forem trabalhadores as condições de acesso e permanência na escola (BRASIL, 1996).

Mas quem são esses jovens e adultos que têm ocupado os bancos escolares nessa modalidade de ensino? $O$ ensino assegurado a eles pela respectiva lei tem realmente atendido a suas necessidades?

As respostas a essas questões não são tão simples. Sabemos que os educandos que frequentam os cursos da EJA são oriundos, na maioria das vezes, das classes populares. São sujeitos que, geralmente, foram, durante anos, marginalizados e excluídos da sociedade. E, dadas essas condições, são jovens e adultos que não "tiveram acesso ou continuidade de estudos no ensino fundamental e médio na idade própria" (BRASIL, 1996), devido a diferentes razões: por terem que trabalhar para ajudar no sustento da família, pelo difícil acesso à escola, porque não se adaptaram ao ensino regular, entre outras.

A EJA recebe, nesse sentido, alunos que são vistos pela sociedade na condição de excluídos, tanto culturalmente quanto economicamente. Geralmente, esses estudantes são, em sua maioria, pobres, analfabetos, repetentes, trabalhadores, negros, desempregados, etc. E, eles, que, por algum motivo, não frequentaram o ensino regular, trazem ao retornarem ao contexto escolar marcas dessa exclusão, de suas vivências, de suas trajetórias de vida, de aprendizagens e dificuldades.

As condições sociais, políticas e culturais desses jovens e adultos têm condicionado as diferentes concepções de educação que lhes é oferecida. Arroyo (2005) já afirmava que a herança legada pelas experiências de jovens e adultos continuam tão atuais quanto foram nas origens da sua história por volta da década de cinquenta e sessenta e isso ocorre porque, de acordo com o autor, "[...] a condição social e humana dos jovens e adultos que inspiraram essas experiências e concepções continua atual" (ARROYO, 2005, p. 223).

Nesse sentido,

a educação popular, a EJA e os princípios e as concepções que as inspiraram na década de sessenta continuam tão atuais em tempos de exclusão, miséria, desemprego, luta pela terra, pelo teto, pelo trabalho, pela vida. Tão atuais que não perderam sua radicalidade porque a realidade vivida pelos jovens e adultos populares continua radicalmente excludente (ARROYO, 2005, p. 223).

E, compactuando com esse cenário, Soares (2002) afirma que ainda estamos longe de ter uma escola, que de fato, atenda a todos, uma vez que, uma grande maioria das escolas brasileiras ainda hoje é "[...] contra o povo que para o povo" (SOARES, 2002, p. 5), isto é,

[...] o fracasso escolar dos alunos pertencentes às camadas populares, comprovado pelos altos índices de repetência e evasão, mostra que, vem ocorrendo uma progressiva democratização do acesso à escola, não tem igualmente ocorrido a democratização da escola. Nossa escola tem se mostrado incompetente para a educação das camadas populares, e essa incompetência, gerando o fracasso escolar, tem tido o grave efeito não só de acentuar as desigualdades sociais, mas, sobretudo, de legitimá-las (SOARES, 2002, p. 6).

O currículo voltado para a EJA é um exemplo desse fracasso e da permanência da desigualdade. De acordo com Arroyo (2007), a proposta curricular do ensino de jovens e adultos está voltada para o emprego seguro. Nela, busca-se oferecer aos educandos a qualificação em matemática, biologia, física, português, química etc. Não se leva em conta, de acordo com o autor, que esses sujeitos vivem uma vida instável no trabalho. São jovens e adultos populares, de vinte, trinta, cinquenta e sessenta anos que, por exemplo, vivem

\footnotetext{
*Endereço eletrônico: milena.moretto@usf.edu.br
} 
vendendo água, vendendo tudo, no trânsito caótico para assegurar a si e a família um pouco de dignidade.

Dadas essas condições, será que o atual currículo já pré-estabelecido dá aos sujeitos que compõem as salas de aula da EJA as qualificações básicas para o mercado de trabalho que eles atuam? Infelizmente, vemos que o currículo não fora pensado para jovens e adultos que vivem nessa situação, uma vez que a escola sempre esteve organizada para atender a poucos. E, por essas razões, "[...] esse trabalho informal não aparece nos currículos como realidade e como forma de trabalho, nem como horizonte" (ARROYO, 2007, p. 9).

Não queremos dizer, no entanto, que o currículo deve prepará-los apenas para mantê-los na condição que se encontram. Ao contrário, precisamos de um currículo que dê centralidade aos conhecimentos sobre esses mundos do trabalho informal e da sobrevivência; de um currículo que capacite esses estudantes para ter novas formas de trabalho e poder para emancipar dessa instabilidade imposta socialmente; de um currículo que ajude esse aluno a reconhecer sua identidade, sobretudo a identidade coletiva; de um currículo que favoreça o desenvolvimento de conhecimentos e capacidades que fortaleçam esse grupo social para que se tornem menos vulneráveis dadas as relações de poder (ARROYO, 2007).

Há a necessidade, nesse sentido, de pensar e repensar as práticas escolares que estão sendo realizadas no contexto da EJA uma vez que

[...] não podemos esquecer que os jovens $\mathrm{e}$ adultos retornam para a escola com muito custo, depois de percursos tão truncados pelo próprio sistema educacional. Qualquer tentativa de fazer da EJA [...] um centro de formação de competências para um trabalho que não existe, já é um fracasso. É um fracasso como educadores, como EJA, é um fracasso, sobretudo, para os jovens e adultos que esperavam outras capacidades para enfrentar esse trabalho informal de sobrevivência onde estão jogados. Não estamos propondo [...] um currículo para mantê-los na sobrevivência mas para serem mais livres no presente, ter mais opções de superá-la, sem promessas ingênuas de futuro (ARROYO, 2007, p. 12).

Nesse sentido, a EJA pode e deve ser um instrumento de transformação social. Para que isso aconteça, é necessário levarmos em consideração três pontos básicos conforme apontam Pierro, Joia e
Ribeiro (2001): 1) superar a concepção de que a EJA é o espaço de reposição de escolaridade perdida na "idade própria"; 2) deixar de conceber o ensino da EJA a partir de padrões únicos (quase sempre seguindo os parâmetros estabelecidos para a educação de crianças e adolescentes); e, 3) reconhecer que não é apenas na escola que um sujeito aprende, isto é, outros espaços sociais também pode ter potencial formativo.

Cabe-nos problematizar melhor esses três pontos.

Primeiramente, é preciso reconhecer que, durante nossa trajetória de vida, sempre é possível aprender. $\mathrm{O}$ desenvolvimento e o aprendizado ocorrem, de forma interdependente, em todas as fases da existência humana e um dos instrumentos que possibilita esse desenvolvimento é a linguagem, uma vez que qualquer

[...] comunicação não mediatizada pela linguagem ou por outro sistema de signos ou de meios de comunicação, como se verifica no reino animal, viabiliza a comunicação do tipo mais primitivo e nas dimensões mais limitadas (VIGOTSKI, 2009, p. 11).

A linguagem, por muito tempo esteve associada a um instrumento de poder e dominação. Em uma sociedade, que dada a dinâmica econômica e política, individualiza as pessoas, distribui a miséria e concentra os privilégios a poucos, a língua também é reflexo dessa mesma situação, uma vez que, "[...] miséria social e miséria da língua confundem-se e uma engendra a outra, formando o quadro triste da vida brasileira" (ALMEIDA, 1984, p. 13). Já dizia Gnerre (1991, p. 22), que "a linguagem constitui o arame farpado mais poderoso para bloquear o acesso ao poder". Afinal, quantas vezes a escola - preparada para atender a classe privilegiada, utilizou desse instrumento poderosíssimo para inviabilizar o acesso ao poder das classes menos favorecidas? Quantas vezes jovens e adultos deixaram de frequentar a escola porque ouviram dela que não tinham condições de aprender? Quantas vezes o discurso patológico fizeram alguns sujeitos se sentirem incapazes de aprender, de se transformarem, de lutar por uma sociedade menos injusta e excludente?

$\mathrm{Na}$ obra "A construção do pensamento e da linguagem", Vigotski já afirmava que a linguagem "[...] é, antes de tudo, um meio de comunicação social, de enunciação e compreensão" (VIGOTSKI, 2009, p. 11) e, para ele, a aprendizagem também é 
um processo essencialmente social - que ocorre na interação com adultos e companheiros mais experientes, onde o papel da linguagem é destacado - percebe-se que é na apropriação de habilidades e conhecimentos socialmente disponíveis que as funções psicológicas humanas são construídas (FREITAS, 1994, p. 104).

Bakhtin (2010), filósofo russo, considera a linguagem como "[...] um fenômeno puramente histórico" e ideológico. Para ele, sendo de natureza social, qualquer enunciação é determinada pelas condições de produção, pelas intenções do falante, pelo que se deseja atingir no interlocutor dentro de um contexto sócio, histórico e ideológico. A enunciação, nesse sentido, é

[...] o produto da interação de dois indivíduos socialmente organizados e, mesmo que não haja um interlocutor real, este pode ser substituído pelo representante médio do grupo social ao qual pertence o locutor. A palavra dirige-se a um interlocutor: ela é função da pessoa desse interlocutor (BAKHTIN, 2010, p. 116).

Assumir essa concepção de linguagem significa ter um novo olhar para o contexto escolar da EJA. Primeiro, em relação ao respeito às diferenças dialetais. Sabemos que os alunos que procuram os cursos da Educação de Jovens e Adultos, dadas as suas diferenças sociais, econômicas e regionais, trazem consigo diversas variedades linguísticas. Por muitos anos e, infelizmente, ainda, em uma grande parte das escolas, essas diferenças são estigmatizadas, reflexo das condições sociais dos indivíduos. É preciso, pois, reconhecer a importância dos cursos de EJA levar os estudantes a se apropriarem de uma variedade de prestígio, legitimada socialmente, mas viabilizando o respeito às diferentes variedades que os alunos trazem consigo. Tais considerações são necessárias porque

[...] o ensino da língua materna comprometido com a luta contra as desigualdades sociais e econômicas reconhece, no quadro dessas relações entre escola e a sociedade, o direito que têm as camadas populares de apropriar-se do dialeto de prestígio, e fixa-se como objetivo levar os alunos pertencentes a essas camadas a dominá-lo, não para que se adaptem às exigências de uma sociedade que divide e discrimina, mas para que adquiram um instrumento fundamental para a participação política e a luta contra as desigualdades sociais (SOARES, 2002, p. 78).
Em segundo lugar, ao assumir essa concepção de linguagem passamos a compreender melhor as tensões que ocorrem nas diferentes situações sociais: as ideologias, as formas de manipulação, de poder e dominação. No contexto da EJA, ao possibilitarmos essas discussões, estaremos disponibilizando aos estudantes a reflexão e compreensão do aparato social em que estão inseridos e oferecendo, a partir do ensino, do conhecimento e da linguagem, uma arma para que eles possam lutar por melhores condições nessa sociedade tão excludente, lutar para vencer as desigualdades sociais, lutar para transformar suas realidades, que não são individuais, mas coletivas.

Para que isso se torne possível, é preciso olhar para o ensino da EJA para além das padronizações já pré-estabelecidas no contexto educacional. Não é possível ensinar para transformar em um currículo que não considera esses espaços e através de materiais didáticos que tem quase sempre um outro interlocutor que não o aluno da EJA. Não são raros os casos em que as atividades desenvolvidas com os adultos são as mesmas que são aplicadas às crianças. Não é raro vermos alunos da EJA se alfabetizando a partir das parlendas e ou da decoreba do be-a-bá. Não é raro vermos alunos estudando, por exemplo, a história dos bárbaros, a história do imperador ao invés da história dos quilombolas, a história do campo, a história dos negros...

[...] Por que não poderia ser outra história, outra forma de contar a história? Por que não fazemos isso? Porque não consideramos esses coletivos populares como sujeitos de história, mas como pacientes de história. Ou nem pacientes, mas como alguém que deveria conhecer a nossa história. Nos falta a história popular, nos falta montar um currículo de Eja que ajude esses coletivos a se entenderem, a se conhecerem, a saberem de sua história (ARROYO, 2007, p. 18).

É, pois, de fundamental importância reconhecer que o ensino da EJA precisa ser direcionado a esse público específico, isto é, levar em conta à faixa etária desses alunos, o perfil sociocultural e às necessidades de uma educação profissional de qualidade.

O que falta para que a escola não seja democrática apenas no acesso, mas também na permanência é dar "voz" e "vez" a esses estudantes, é reconhecer que, como sujeitos históricos, eles têm uma trajetória de vida, têm suas potencialidades, são 
sujeitos que aprendem, são sujeitos que podem se transformar.

Sendo assim, esses sujeitos trazem ao retornarem à escola muitos conhecimentos que adquiriram através de suas experiências de vida. E, diante disso,

enquanto a escola pensa que fora dela, dos seus currículos e saberes não há salvação - nem cidadania e conhecimentos, nem civilização e cultura - a educação popular nos alerta que o correto é entender a escola como um dos espaços e tempos educativos, formadores e culturais. Tempo imprescindível, porém não único. (ARROYO, 2005, p. 228).

Diante dessas considerações, para que tenhamos um ensino da EJA mais dialógico, mais libertador e emancipatório, é preciso que

a escola reconheça o educando da EJA como sujeito de aprendizagens, com potencialidades múltiplas para aprender e desenvolver várias e diversas inteligências e habilidades mediadas pelo diálogo e interação com o outro (professor, sociedade e tecnologias). É fundamental compreendermos que todos têm direito de aprender e que a aprendizagem é uma condição humana e está presente para além das salas de aulas, está nas múltiplas trajetórias de vida, de saberes sociais, de práticas de sobrevivência e de experiências profissionais dos educandos da EJA (ABRAMOWICS, 1997, apud SOUZA e SILVA, 2011, p. 101).

Se a escola não mudar, portanto, o conceito de língua, de sujeito, de currículo e, principalmente, de quem são os alunos que ocupam os bancos escolares da EJA, ela continuará estigmatizando aqueles que a sociedade já reprovou e curtindo o fracasso de seus projetos.

\section{Referências}

ALMEIDA, M. J. de. Ensinar Português? In: GERALDI, J. W. (org.). O texto na sala de aula: leitura \& produção. 6. ed. Cascavel: Assoeste, 1984.

ARROYO, M. A educação de jovens e adultos em tempos de exclusão. In: BRASIL, Ministério da Educação. Construção coletiva: contribuições à educação de jovens e adultos. 2. ed. Brasília: UNESCO, MEC, RAAAB, 2005.

Balanço da EJA: o que mudou nos modos de vida dos jovens-adultos populares? REVEJ@:

Revista de Educação de Jovens e Adultos, v. 1, n. 0, p. 1-18, ago, 2007.

BAKHTIN, M. Marxismo e filosofia da linguagem: problemas fundamentais do método sociológico da linguagem. 14. ed. São Paulo: Hucitec, 2010.

BRASIL. Ministério de Educação e Cultura. Lei de Diretrizes e Bases da Educação Nacional - Lei no 9394/96, de 20 de dezembro de 1996. Brasília: MEC, 1996.

FREITAS, M. T. de A. Vygotsky e Bakhtin psicologia e educação: um intertexto. São Paulo: Ed. Ática, 1994.

GNERRE, M. Linguagem, escrita e poder. 3. ed. São Paulo: Martins Fontes, 1991.

PIERRO, M. C. D.; JOIA, O.; RIBEIRO, V. M. Visões da educação de jovens e adultos no Brasil. Cadernos Cedes, ano XXI, n. 55, p. 58-77, nov2001.

SOARES, M. Linguagem e escola: uma perspectiva social. 17 ed. São Paulo: Editora Ática, 2002.

SOUZA, G. L. R.; SILVA, L. A. da. A educação de jovens e adultos como instrumento de transformação social. Revista Brasileira de Educação e Cultura, n. IV, p. 89-110, jul-dez, 2011.

VIGOTSKI, L. S. A construção do pensamento e da linguagem. 2. ed. São Paulo: Editora WMF Martins Fontes, 2009.

\section{Sobre a autora}

Milena Moretto é licenciada em Letras, Mestre e Doutora em Educação pela Universidade São Francisco. Atualmente, é professora e pesquisadora do Programa de Pós-graduação Stricto Sensu em Educação da Universidade São Francisco (USF).

Recebido em setembro de 2016.

Aprovado em novembro de 2016. 